\title{
ENTRE FORMALISMO Y THEOLOGICAL READING: GARZÓN VALDÉS, FRANCISCO SUÁREZ Y LA INTERPRETACIÓN DE LA LEY
}

\author{
Pierluigi Chiassoni \\ Universidad de Génova
}

RESUMEN. Después de una rápida exposición crítica de las tesis que Garzón Valdés atribuye a Suárez en lo que concierne a la interpretación jurídica, voy a sugerir, a mi vez, una lectura de la teoría de Suárez, mucho menos caritativa —y, si se quiere, algo más radical- de la proporcionada por Garzón Valdés.

Palabras clave: Ernesto Garzón Valdés, interpretación jurídica, Francisco Suárez.

ABSTRACT. After providing a critical account of the views Ernesto Garzón Valdés ascribes to Suárez as to legal interpretation, a different, less charitable, reading of Suárez's theory will be outlined.

Keywords: Ernesto Garzón Valdés, legal interpretation, Francisco Suárez. 


\section{PREFACIO}

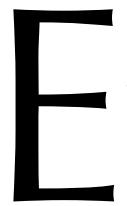

n la extensa obra iusfilosófica de Ernesto GARZÓN VALDÉS, la interpretación jurídica ocupa —si no me equivoco- el corto espacio de un ensayo, publicado por primera vez en castellano hace treinta años: «Las palabras de la ley y su interpretación: algunas tesis de Francisco Suárez» ${ }^{1}$.

La parte que SUÁREZ dedica a la interpretación de las «leyes humanas» (leyes civiles y leyes canónicas) en su Tractatus de legibus ac Deo legislatore constituye un verdadero tratado en el tratado y, cabe decir, uno de los estudios más largos, articulados y finos de su época².

En su escrito, GARZÓN VALDÉS arroja luz sobre unos rasgos en la teoría de la interpretación jurídica de SUÁREZ, persiguiendo exitosamente un doble fin: (i) destacar la actualidad de SUÁREZ (pues plantea cuestiones todavía «recurrentes» y proporciona soluciones similares a las de «algunos autores contemporáneos») y (ii) sugerir, más en general, la importancia de no olvidar nunca la lección de los clásicos.

Después de una rápida exposición crítica de las tesis que GARZÓN VALDÉS atribuye a SUÁREZ $(\$ 1)$, voy a sugerir, por mi parte, una lectura de la teoría de la interpretación de SuÁrez (\$2). Se tratará, cabe decirlo, de una lectura mucho menos caritativa —y, si se quiere, algo más radical— de la proporcionada por GARZÓN VALDÉs. Espero, sin embargo, que el Maestro no percibirá mi lectura como totalmente desdichada, sino como un (modestísimo) homenaje a su obra y a su ejemplo.

\section{LAS TESIS DE SUÁREZ, SEGÚN GARZÓN VALDÉS}

GARZÓN VALDÉS atribuye a SUÁREZ cuatro tesis básicas acerca de la interpretación de las leyes:

a) la «tesis de la desmitologización» (Tesis-1);

b) la «tesis del legislador justo y racional» (Tesis-2);

c) la «tesis del carácter prescriptivo de la interpretación doctrinal» (Tesis-3);

d) la «tesis de la interpretación como cambio» (Tesis-4).

${ }^{1}$ GARZÓN VALDÉs, 1977: «Las palabras de la ley y su interpretación: algunas tesis de Francisco Suárez», Dianoia, pp. 30-41; publicado también en GARZÓN VALDÉs, 1993: Derecho, ética y política, Madrid: Centro de Estudios Constitucionales, pp. 117-129. Algunas consideraciones sobre la naturaleza no descriptiva de los juicios interpretativos pueden leerse en GARZÓN VALDÉs, 1995: «Some Remarks on Bulygin's "Cognition and Interpretation of Law"», en GIANFORMAGGIO, y PAULSON, S. (comps.) 1995: Cognition and Interpretation of Law, Torino: Giappichelli, pp. 283-284. La más reciente bibliografía de E. GARZÓN VALDÉs puede leerse, según creo, en el Apéndice a COMANDUCCI, 2006: Constitución y teoría del derecho, Cátedra Ernesto Garzón Valdés, R. VÁzQUEZ y R. ZIMMERLING (coords.) 2007: México: Fontamara, pp. 133-149.

2 SuÁREZ, 1612: Tractatus de legibus ac Deo legislatore, tr. sp., Tratado de las Leyes y de Dios legislador, Madrid: Instituto de Estudios Políticos, 1968, Libro VI. Para darse cuenta de la extensión no común del tratado suarista sobre interpretación, puede ser útil compararlo, por un lado, con el Tractatus de interpretatione legum de Stefano DE FEDERICI (en Tractatus de universi iuris, vol. I, Venetiis, 1584), que representa un arquetipo del tratado de Suárez, y por otro lado, con el capítulo que Samuel PuFENDORF dedica a la interpretación en el De iure naturae ac gentium (LuND, 1672). 
I. La Tesis-1 — «tesis de la desmitologización del lenguaje», o sea tesis del convencionalismo lingüístico y del rechazo de la «concepción mágica del lenguaje» o concepción esencialista de la relación entre palabras y conceptos- sostiene que el significado de toda palabra (ordinaria o técnica) es arbitrario y resulta de una imposición convencional («Las palabras de la ley», p. 118).

Esta tesis, según subraya GARZÓN VALDÉS, tiene en SUÁREZ un corolario y algunas consecuencias notables.

El corolario sostiene que «no hay nada que nos ate fatalmente a un significado originario, sino que éste puede ser modificado por el uso» («Las palabras de la ley», p. 119).

De la Tesis-1, junto con su corolario, se siguen cuatro consecuencias.

Consecuencia-1: No tiene sentido procurar describir el significado «verdadero» de las palabras de la ley, porque no hay tal cosa como el significado verdadero de las palabras (no-esencialismo lingüístico).

Consecuencia-2: Las palabras de la ley no tienen un significado estático, que sea dado de una vez para siempre, sino un significado dinámico, que puede cambiar, y cambia, en el tiempo (dinamismo semántico).

Consecuencia-3: Quien quiera conocer el significado de las palabras no puede limitarse a considerarlas aisladas de sus contextos de uso (contextualismo epistemológico).

Consecuencia-4: $\mathrm{Si}$ «las palabras de la ley son, en gran medida, las del lenguaje ordinario, entonces es importante considerar más de cerca las características de este lenguaje» (relevancia cognoscitiva del lenguaje ordinario: «Las palabras de la ley», p. 120).

Más precisamente, según sostiene GARZÓN VALDÉS, un análisis del lenguaje jurídico y de su interpretación desde la perspectiva del lenguaje ordinario permitiría darse cuenta de unos rasgos no secundarios de ellos.

En primer lugar, del mismo modo que en el lenguaje ordinario, los problemas básicos que se plantean, y pueden plantearse, en la interpretación de las leyes surgen de la ambigüedad y de la vaguedad semántica de las palabras de la ley.

En segundo lugar, del mismo modo que en el lenguaje ordinario, los enunciados de las leyes tienen, y pueden tener, un sentido claro (cuando no hay ni ambigüedad, ni vaguedad), y entonces el «escepticismo total» ante las normas queda injustificado —y SuÁREZ correctamente no se compromete con él.

En tercer lugar, del mismo modo que en el lenguaje ordinario detrás de los enunciados comunes está la mente de un hablante común, en el Derecho, detrás de las leyes, está la mente del legislador.

En cuarto lugar, y por último, la interpretación es necesaria cuando las palabras de las leyes son ambiguas o vagas y de esta necesidad «nace [...] la jurisprudencia y la "declaración doctrinal”» («Las palabras de la ley», pp. 120-121).

II. Bajo el rótulo de «tesis del legislador justo y racional» (Tesis-2), GARZÓN VALDÉS recoge aparentemente dos diferentes directivas de interpretación (prescripciones interpretativas). 
(1) La primera directiva parece orientar a los intérpretes hacia formas de interpretación derogatoria (interpretatio abrogans) de las leyes:

La interpretación ha de ser de leyes que existen, que son válidas y obligatorias, es decir, de leyes justas, razonables y útiles; [...] por lo tanto, lo primero que habrá de resolver el intérprete es si la ley en cuestión es justa, útil y razonable en general, y además, si es justa, útil y razonable su aplicación a un caso determinado;

más precisamente, la primera directiva prescribe que las leyes injustas, inútiles, y/o no razonables no deben ser interpretadas, $n i$, en consecuencia, aplicadas, sino tratadas por los intérpretes tamquam non essent.

(2) La segunda directiva, sobre el presupuesto de que una ley fuese originariamente una (verdadera) ley (es decir, justa, útil y razonable), prescribe que:

la ley debe ser interpretada de manera tal que siga siendo ley, es decir, justa, útil y razonable («Las palabras de la ley», pp. 122-123, las cursivas son mías).

III. Bajo el rótulo de «tesis del carácter prescriptivo de la interpretación doctrinal» (Tesis-3), GARZÓN VALDÉS se refiere al hecho de que las convergencias interpretativas pueden convertirse en costumbres que vinculan a los intérpretes ( LLas palabras de la ley», p. 123; SUÁrEZ, F.: Tractatus de legibus, VI, cap. 1.4, 1.6).

Cabe decir que, desde una perspectiva (obstinadamente) analítica, la tercera tesis de SuÁREZ podría ser entendida, según creo, en al menos tres formas diferentes:

i) Como una tesis de teoría general (descriptiva) de las fuentes del Derecho, según la cual, de hecho, en los sistemas jurídicos positivos la costumbre interpretativa es/puede ser una fuente auxiliar del Derecho, que complementa la fuente ley;

ii) Como una tesis de teoría normativa de las fuentes del Derecho, según la cual los interpretes deben seguir las interpretaciones usuales, i.e., resultantes de la perdurable convergencia de las opiniones interpretativas de los doctores y de los jueces.

Aparentemente, las dos versiones de la Tesis-3 ahora mencionadas están entrelazadas sin más en el discurso de SUÁrEZ, donde no hay, en general, alguna clara y consciente distinción entre «teorías» y «ideologías» de la interpretación (y de las fuentes del Derecho).

Sin embargo, esta distinción —aparentemente descuidada también por lo mismo GARZÓN VALDÉS - provee, en mi opinión, la clave para disfrutar totalmente de la «teoría» de SUÁREZ en sus dos dimensiones básicas, teórica y práctica, y apreciar aún más su actualidad.

IV. En fin, bajo el rótulo de «tesis de la interpretación como cambio» (Tesis-4), Garzón Valdés recoge nuevamente —en mi opinión, sin destacarlo en forma adecua$\mathrm{da}$ - unas directivas de interpretación, que constituyen las piezas finales de lo que podría llamarse el «código interpretativo» de SUÁREZ.

Para entender el alcance y la posición de estas últimas directivas en el código de Suárez, es preciso mencionar que Suárez distingue cuatro situaciones que pueden presentarse, cuando se trata de interpretar una ley:

(S1) La ley tiene un significado propio (ordinario o técnico) claro (ni ambiguo, ni vago), pero es insalvablemente inválida: i.e., cualquier significado de la ley es «insalvablemente» injusto, absurdo o ilusorio («Las palabras de la ley», p. 124); 
(S2) La ley tiene un significado propio (literal) claro y, además, es válida: i.e., el claro significado literal es justo, útil, y razonable;

(S3) La ley tiene un significado propio claro, pero es inválida, aunque salvablemente, a nivel de su aplicación a un caso individual —i.e., la aplicación de la ley en su sentido literal sería injusta, absurda, y/o inútil;

(S4) La ley tiene un significado propio dudoso (ambiguo y/o vago), pero es válida: i.e., el dudoso significado literal de la ley es justo, útil y razonable.

Ahora bien, en las situaciones como S1, el intérprete debe (deónticamente) considerar la ley como inválida y no obligatoria en absoluto - como una ley de la cual no se puede sacar alguna norma válida y que, por lo tanto, debe ser dejada de lado (tesis del legislador justo y racional).

En las situaciones como S2, el intérprete debe (deónticamente) limitarse a aplicar la ley al caso individual en su interpretación literal, haciendo obra de interpretación declarativa.

En las situaciones como S3, el intérprete debe (deónticamente) hacer trabajo de interpretación correctiva (interpretatio correctiva, en la forma sea extensiva o bien restrictiva), rechazando el significado propio (literal) inválido en favor de otro significado (más amplio o más restrictivo), conforme a justicia, utilidad y razón, sobre el supuesto invencible (o bien la presunción absoluta, iuris et de iure) de que el legislador, en cuanto autor justo y racional, quiso poner una ley con un significado diferente de su significado literal.

En las situaciones como S4, en fin, el intérprete debe (deónticamente) resolver las dudas semánticas (ambigüedad y vaguedad) acerca del significado de la ley en medida conforme, nuevamente, al supuesto invencible de un legislador justo y racional.

Nótese que, en las situaciones S2, el intérprete debe (deónticamente) jugar, todo considerado, un papel «declarativo», en fuerza de consideraciones normativas sustanciales: es decir, porque, en hipótesis, «littera et [justa, utilis et rationabilis, ndr] voluntas pari passu ambulant», según la caracterización de la interpretatio declarativa proporcionada, por ejemplo, por HeINECKE (HEINECCIUS).

En las situaciones S3, en cambio, el intérprete, aún si podría de hecho jugar un papel simplemente pasivo, debe (deónticamente) proceder a una re-interpretación correctiva de la ley, guiada, como hemos visto, por la invencible presunción hermenéutica del legislador ideal, justo y razonable.

En fin, en las situaciones S4, el intérprete, que tenga el deber absoluto de decidir (prohibición del non liquet), no puede de hecho jugar un papel simplemente pasivo (porque, en hipótesis, la ley no tiene un significado determinado), y debe (deónticamente) superar las indeterminaciones semánticas de la ley, procediendo a una interpretación (que podríamos llamar) supletoria, guiada, nuevamente, por la presunción hermenéutica del legislador ideal, justo y razonable.

Las directivas interpretativas que, según SuÁREZ, deben regir la interpretación de la ley en las situaciones S3 y S4 constituyen el contenido de lo que GARZÓN VALDÉS llama «tesis de la interpretación como cambio». Esto es así porque, en ambos casos,

el intérprete ha de realizar el reajuste necesario de las palabras de la ley, sea poniendo fin a su ambigüedad o vaguedad, sea ampliando o restringiendo el significado de la ley, es de- 
cir, cambiando la ley de forma tal que su aplicación sea justa y razonable («Las palabras de la ley», p. 124, las cursivas son mías);

lo que, como GARZÓN VALDÉS esclarece poco después, el intérprete hace (debe hacer) usando su «prudencia y equidad» («Las palabras de la ley», p. 126).

$\mathrm{Al}$ final de su reconstrucción, GARZÓN VALDÉS se detiene a subrayar el valor actual de la teoría de SUÁREZ bajo dos perfiles:

1) La idea de que «el fundamento normativo de validez de un sistema de reglas de conducta, sean éstas morales o jurídicas, es postulado dogmáticamente»;

2) Una clara, verdadera - y realista - descripción de las tareas de la dogmática jurídica, que «el jurista contemporáneo», con su pretensión de simplemente «describir la ley», no siempre comparte («Las palabras de la ley», p. 129).

\section{SUÁREZ Y LA INTERPRETACIÓN DE LA LEY: FORMALISMO Y THEOLOGICAL READING}

En su ensayo, Ernesto GARZÓN VALDÉS muy oportunamente ha destacado la importancia de no olvidarnos, en nuestras investigaciones iusfilosóficas, de la poderosa, y siempre instructiva, lección de los clásicos, apoyando su sugerencia en la evidencia proporcionada por la teoría de la interpretación jurídica de SUÁREZ.

Me parece, sin embargo, que la lectura de SuÁrez bosquejada por GARZÓn VALDÉS tiene, por lo menos, tres rasgos discutibles.

En primer lugar, GARZÓN VALDÉS reconstruye la teoría de SUÁREZ a través de las gafas engañosas de aquella teoría (cognoscitiva) de la interpretación jurídica que hoy en día suele llamarse «teoría mixta» («intermedia» o «ecléctica»).

En segundo lugar, GARZÓN VALDÉS proporciona una lectura demasiado caritativa de la teoría de SUÁREZ, en lo que concierne a sus presupuestos metaéticos y, en consecuencia, ofrece una lectura desviante de la posición de la teoría de SUÁREZ en el marco de las teorías cognoscitivas de la interpretación.

En tercer y último lugar, GARZÓN VALDÉS proporciona una lectura demasiado caritativa de la teoría de Suárez, en lo que concierne a su dimensión práctica, y más precisamente, a su ideología de la interpretación (y código interpretativo).

\subsection{Las gafas engañosas de la teoría mixta}

GARZÓN VALDÉS reconstruye la teoría de Suárez a través de las gafas engañosas de la teoría mixta:

analizado el significado de las palabras de la ley, tomadas éstas en su sentido propio, ordinario o técnico, no plante[a] su aplicación ningún problema de injusticia, irrazonabilidad o inutilidad. En este caso, la interpretación tiene una función puramente «declarativa»: el intérprete se limita a describir el contenido de la prescripción en cuestión [...]

De los tres casos presentados, el más interesante es el último [que coincide con las situaciones $\mathrm{S} 3$ y $\mathrm{S} 4$ que hemos visto arriba, ndr] ya que en el primero [S1, ndr] no cabe inter- 
pretación alguna y en el segundo [S2, ndr], su función es puramente declarativa («Las palabras de la ley», p. 124, las cursivas son mías).

Ahora bien, aunque SuÁREZ mencione la opinión, en tal sentido, de Bartolo (De legibus, VI, 7.1), en SUÁREZ —y en los juristas del siglo XVI-XVII- lo que se engloba bajo el rótulo de «interpretación declarativa» (interpretatio declarativa) no es una actividad «simplemente declarativa», ya sea, simplemente descriptiva del contenido (semántico) de una ley.

La interpretación declarativa-producto, por supuesto, es una norma que, en hipótesis, corresponde al claro significado literal (o propio) de una ley.

Pero, detrás de esta interpretación declarativa-producto no hay simplemente el conocimiento, por el intérprete, de los usos lingüísticos y su pasiva adecuación a ellos. Hay también — como el mismo GARZÓN VALDÉS se cuida de señalar- un juicio de validez sustancial sobre el claro sentido literal de la ley en cuestión; un juicio de validez que, según SuÁREZ, se funda, y debe fundarse, sobre criterios de validez extra-positivos y meta-positivos, que son en ultima instancia proporcionados por los principios del derecho natural católico.

Esto sugiere a su vez que, en SUÁREZ, los problemas interpretativos jurídicos no derivan solamente del lenguaje: no son sólo, ni principalmente, problemas de ambigüedad y vaguedad de las palabras de las leyes, sino son también, y principalmente, problemas de injusticia, irrazonabilidad, y inutilidad, que el intérprete puede, y debe, resolver bajo el principio hermenéutico del legislador justo y racional.

En suma, pueden destacarse, según parece, las siguientes conclusiones.

1) La interpretación declarativa de SUÁREZ, a pesar de su tradicional y engañoso apellido, no coincide ni con la interpretación como puro acto cognoscitivo, de la cual hablan Herbert HART, Genaro CARRIÓ, y Eugenio BULYGIN, ni con el «simple understanding» del cual habla, aún de recién, Andrei MARMOR.

2) Por el contrario, la interpretación declarativa de SUÁREZ es una operación compleja, que incluye delicadas y difíciles valoraciones sobre la justicia, razonabilidad y utilidad de las leyes, y en la cual el intérprete no es simplemente un hablante de un lenguaje natural, sino es ya, y totalmente, un técnico y, yo añadiría, un político del Derecho.

3) Detrás de la concepción de la interpretación declarativa de SUÁREZ está la idea de que nunca el intérprete de las leyes es - y debe ser- un puro describidor (y seguidor) de usos lingüísticos. Lo que, a su vez, pone en tela de juicio las teorías mixtas, según las cuales hay casos en que la interpretación es simplemente cognoscitiva (descriptiva) del significado literal de las leyes.

\subsection{Una lectura demasiado caritativa y desviante de los presupuestos meta-éticos y de la posición teórica de Suárez}

Al final de su ensayo, GARZÓN VALDÉS sugiere una lectura de la teoría de la interpretación jurídica de Suárez como teoría que, en su dimensión cognoscitiva, pertenece al marco de las teorías realistas o bien antiformalistas: 
La afirmación del carácter prescriptivo y de la función correctora que Suárez atribuye a la interpretación parece ser también una buena descripción de la tarea que cumple la dogmática jurídica. El intérprete «optimiza» la ley, actualizándola no sólo temporalmente, sino en el sentido aristotélico de la palabra, es decir, perfeccionándola y cambiándola si es necesario para evitar que sea absurda (contradictoria), inútil (redundante o de imposible cumplimiento) e injusta. En Suárez, aparecen explícitas las bases de esta actitud frente al problema de la interpretación. El jurista contemporáneo suele no ser tan claro en este punto: bajo el manto de una pretendida descripción de la ley, lleva a cabo exactamente la misma tarea que Suárez declara sin tapujos («Las palabras de la ley», p. 129, las cursivas son mías).

Esta lectura actualizadora - y, cabe subrayarlo, en sentido realista— de la teoría de SuÁREZ parece, sin embargo, demasiado caritativa. Por las siguientes razones.

La teoría de SUÁREZ —en su dimensión cognoscitiva— es una teoría formalista. Se trata, en verdad, de un ejemplo fulgente de formalismo interpretativo.

Según SUÁREZ — como subraya el mismo GARZÓN VALDÉS («Las palabras de las leyes», p. 128)— las leyes tienen, para cada caso individual, un significado verdadero. Este significado es el significado justo, útil y razonable, a la luz de los principios de justicia, utilidad, y racionalidad sancionados, en última instancia, por los principios del derecho natural católico; por supuesto, como hemos visto antes, este significado puede coincidir con el significado propio (literal) de las leyes, pero no siempre es así.

Según SuÁREZ, además, no sólo las leyes tienen un significado verdadero para cada caso de su aplicación, sino que tal significado puede ser conocido por los intérpretes, sobre la base de su «virtud y prudencia».

¿Por qué, entonces, proporcionar una lectura de SuÁREZ como la de un realista avant la lettre?

Esto nos lleva a considerar como GARZÓN VALDÉS ha reconstruido los presupuestos metaéticos de la teoría de Suárez:

es claro que la suposición de una ley divina como criterio absoluto de justicia puede parecer extraña a quien no sustente una concepción iusnaturalista de tipo teológico. Sin embargo, si se piensa que los principios morales son aceptados dogmáticamente como hipótesis de comportamiento y se sustituye la expresión «ley divina» o «ley natural» por «principio moral», la extrañeza disminuye. Más aún: no es incorrecto sostener que el fundamento normativo de validez de un sistema de reglas de conducta, sean éstas morales o jurídicas, es postulado dogmáticamente («Las palabras de la ley», p. 129, la cursiva es mía).

En efecto, si asumimos — como GARZÓN VALDÉS aparentemente hace aquí- que los criterios morales últimos de corrección interpretativa son «postulados dogmáticamente» («Las palabras de la ley», p. 129), parece natural llegar a la conclusión de que intérpretes diferentes pueden postular principios últimos diferentes, de forma que no hay en absoluto un verdadero significado de las leyes, como parece asumir SUÁREZ, sino que sólo hay significados correctos relativos a determinados criterios últimos, que son plurales y alternativos, y cuya utilización depende, en última instancia, de una elección irracional por los intérpretes.

En otras palabras: la teoría de SUÁREZ puede ser vista como incluyendo una descripción verdadera, y realista, del fenómeno interpretativo si, y si sólo si, le quitamos sus presupuestos de objetivismo y cognoscitivismo metaéticos. 
Sólo bajo esta condición —según creo, totalmente inaceptable por SUÁREZ— la teoría de SUÁREZ podría ser vista como un ejemplo temprano de una teoría desencantadamente realista, a la manera de KELSEN y de los realistas analíticos continentales: i.e., como una teoría que pone en tela de juicio no sólo cualquier forma de formalismo (o cognoscitivismo) interpretativo, sino también las así llamadas teorías mixtas.

\subsection{Una lectura demasiado caritativa de la ideología suarista de la interpretación}

Aún si aceptamos — según la sugerencia de GARZÓn VALDÉS— un SuÁreZ dispuesto a considerar los principios del derecho natural católico como simples objetos de un postulado dogmático (y entonces, un Suárez pluralista en lo que concierne a los valores morales últimos y la metaética), queda todavía un lado tenebroso en su teoría.

Me limitaré, aquí, a mencionarlo.

En cuanto teoría normativa de la interpretación de las leyes civiles, la teoría de SUÁREZ, gracias a su patente compromiso - teológico y teocrático- con el derecho natural de la tradición católica, constituye una seria amenaza para los derechos y las libertades de los ciudadanos de los Estados constitucionales de Derecho, puesto que prescribe a los intérpretes proceder en cada caso a un theological reading de las fuentes del Derecho, incluso la constitución.

Por lo tanto, hay fuertes razones prudenciales para rechazar sin más la teoría de SUÁREZ, en cuanto vehículo de la subrepticia instauración de aquel estado «sanamente» o «justamente» laico ahora en días tan apreciado — et pour cause- por los altos mandos de la Iglesia de Roma. 